\title{
Dank an Ludwig Waldmann anläßlich seines 65. Geburtstages
}

Ludwig Waldmann ist außer mir der einzige Überlebende von den sechs Männern, deren Namen auf dem Titelblatt des im Jahre 1946 erschienenen ersten Bandes der Zeitschrift für Naturforschung zu lesen sind. Sie haben dieser Zeitschrift zu ihrem Entstehen verholfen und ihr von Anfang an mit Rat und Tat beigestanden. Die anderen vier "Gründer" waren Arnold Sommerfeld, Klaus Clusius, Alfred Kühn und Hans Friedrich-Freksa. Auch gibt es bereits im ersten Heft der Zeitschrift für Naturforschung eine Arbeit von Ludwig Waldmann, und seitdem findet man in fast jedem Band dieser Zeitschrift seine Beiträge. Dies ist Grund genug, ihm einmal gleichsam öffentlich für seine treue Mitwirkung zu danken, und sein 65. Geburtstag, den er am 8. Juni 1978 gefeiert hat, gibt einen willkommenen Anlaß dazu.

An seinen Arbeiten muß man bewundern, mit welcher Meisterschaft er als Denker bis zur endgültigen Lösung der Probleme vordringt, deren Klärung er sich vorgenommen hat, und wie er seine oft sehr subtilen Gedankengänge und Ergebnisse in leserfreundlicher und formvollendeter Weise niederzuschreiben weiß. Das Ansehen jeder Zeitschrift wird durch solche Arbeiten gehoben, und das gute Beispiel verfehlt seine Wirkung auf die Forschungsweise und den Schreibstil anderer Autoren nicht.

Als einem der Herausgeber fiel es ihm zu, sich gerade der schwierigen Manuskripte anzunehmen, besonders aus den Gebieten der irreversiblen Thermodynamik, statistischen Mechanik und kinetischen Gastheorie. Dafür hätte man in Deutschland keinen kompetenteren Referenten finden können. Viele Autoren haben von seinen Einwänden gelernt und haben seine Verbesserungsvorschläge dankbar befolgt, und so manche Arbeit ist erst durch seine Hilfe in korrekter und präsentabler Form in die Welt hinausgegangen.

Alle seine Leser und die Autoren und Mitarbeiter der Zeitschrift für Naturforschung, die sich seiner vielfältigen Belehrung und großzügigen Hilfe erfreuen durften, hoffen, daß es noch lange so weiter gehen möge und bringen dem geliebten und verehrten Meister zugleich mit ihrem wärmsten Dank für sein zurückliegendes Wirken, die herzlichsten Glückwünsche für die kommenden Jahre seines Lebens dar.

Alfred Klemm 
Nachdruck - auch auszugsweise - nur mit schriftlicher Genehmigung des Verlages gestattet Verantwortlich für den Inhalt: A. KLEMM

Satz und Druck: Konrad Triltsch, Würzburg 